\title{
Can Pikachu Die? Online Fan Conspiracy Theories and the Pokémon Gaming Universe
}

\author{
Lincoln Geraghty
}

\begin{abstract}
Pokémon, Nintendo's globally recognized transmedia video game franchise, has an established international fan community. Regular releases of new toys, games, trading cards, books, television series, feature length films and now the Pokémon Go mobile app introduce new characters, creatures and extend the Pokémon narrative universe. Although, a consideration of the transmedia aspects of the Pokémon franchise is important, this paper focuses more on the relationship between the narrative (the story of Ash's travels meeting new characters and pokémon) and an ever-growing and creative fan culture online. I explore how fans use the narrative structure of the games and television series to create their own fanfic to fill in blanks and gaps in the backstories of characters and develop their own theories behind mysteries surrounding different versions of the games. The prevalence and popularity of these conspiracy theories suggest that fans are in a constant struggle to seek some sort of control over the Pokémon story, finding understanding within the universe of the games. While the Pokémon canon is expanded and routinely added to with new characters and regions created for new games, fan created content and conspiracy theories serve to weave a more complex narrative web that highlights the importance of fan agency within the gaming community.
\end{abstract}

\section{Keywords}

Pokémon, fan fiction, canons, fanons, conspiracy theories, transmedia, video games

Pokémon, the Japanese trading card craze turned computer game and merchandising phenomenon, has captivated millions of fans across the globe for 20 years. ${ }^{1}$ Although loved by its fans it has also attracted plenty of criticism from parents and cultural commentators who have focussed their attention on the hypercommercialism of the Nintendo brand and the supposed commodification of childhood that having to "catch'em all" encourages. As well as the toys, video games, cards, and popular television series based on the games there have been more than 15 feature length films (the majority straight to DVD) that introduce new characters, creatures and extend the Pokémon narrative universe. In many ways

\footnotetext{
1 Pokemon was released in Japan as a game cartridge for Nintendo's Game Boy on February $27^{\text {th }}$ 1996. The trading cards, TV series and other merchandising spin offs came later, once the game was popular. It was exported to the United States in 1998, only this time the merchandise was launched at the same time so as to capitalize on the movement and appeal (Kent, 2001: 566-567).
} 
Pokémon is the prime of example of a contemporary "commercial supersystem of transmedia intertextuality," as defined by Marsha Kinder (1991: 3), where the children's brand spreads out across multiple media platforms and commodities, driven by the central story-arc of Ash's ongoing journey to become a Pokémon Master. Similarly, Marc Steinberg (2012) and Colin B. Harvey (2015) have extended Henry Jenkins' (2006) work on convergence and analysed the phenomenon of transmedia storytelling, an entertainment industries strategy currently informing the creation and development of mega franchises like Star Wars and the Marvel Cinematic Universe. Pokémon is a transmedia story, Ash's narrative journey crosses over from video game to television to comics and manga to the toys and other merchandise children and fans can watch, play and collect.

Within this narrative, Ash's physical journey to new regions (catching new pokémon) plays out in conjunction with his more emotional and personal journey, learning life lessons and making new friends (never separated from his best friend, Pikachu). Indeed, in a recent chapter for the collection Children's Film in the Digital Age I argue that the narrative within the Pokémon films and TV series is presented as "a culture of challenge" targeted "at a youthful audience, using myth and metaphor to tell didactic stories that inform, educate and entertain" (Geraghty, 2015: 86). This didacticism may not necessarily be what adults think can come from a simple game but nonetheless these are lessons deeply embedded in the cultural framework of the mythic quest motif. It crosses transnational borders and is clearly translatable to both Japanese and western audiences. Pokémon is part of a long tradition of children's literature and media which has communicated important social and cultural messages to its readership and audience over many decades. The narrative framework of Pokémon suggests that Ash's physical and emotional journey 
to becoming a Pokémon Master (at least in the US version) is a model for children to follow in their lives. Using the card and computer games in conjunction with watching the characters go through trials and ordeals on screen, children are able to play at being the hero - making those sacrifices to win and learning how to be a socially aware citizen within a global media society.

While a consideration of the educational aspects of the Pokémon brand is important, I want to focus more on the relationship between transmediality, the collecting ethos (catching and training pokémon), the narrative (the story of Ash's travels meeting new characters and pokémon), and how this informs an evergrowing and creative fan culture online. Building on David Buckingham and Julian Sefton-Green's (2003: 394) argument that the "catch'em all" ethos mediated through watching, trading and playing helps children develop the new media “'multiliteracies' that are now essential for democratic participation," I explore how fans use the narrative structure of the games and television series to create their own fanfic to fill in blanks and gaps in the back stories of characters and develop their own theories behind mysteries surrounding different versions of the games. Hacked game cartridges, fake Easter eggs and alternate dialogue for the various games released by Nintendo become sought-after in the fan community as their legend turns them into the equivalent of ghost stories and tall tales. Online fan conspiracy theories that build up around such game modding and narrative retelling suggest that fans are in a constant struggle to seek some sort of control over the Pokémon story, finding understanding within the universe of the games.

I would argue that such activity is symptomatic of how Matt Hills describes the appeal of cult television texts, whereby an "endlessly deferred narrative" is set within a "hyperdiegesis" or expanded universe which allows for multiple versions, multiple 
endings, and multiple characters (2002: 134). However, while Pokémon's narrative is expanded and routinely added to with new pokémon and regions created for new games, fan created content and theories serve to weave a more complex narrative web that highlights the importance of fan agency within the gaming community. Furthermore, the rapidity and volume of such paratextual material is indicative of contemporary game fan culture where self-created narratives disseminated online allow for greater interpretation and interaction with both text and subtext, context and metatext. Indeed, Joseph Tobin argues that throughout the initial craze for Pokémon there were thousands of unofficial websites and other spin-off fan activities that challenged producers' authorship and control of the franchise and characters (2004: 274-277). For Jon Dovey and Helen W. Kennedy, fan art comes in various guises, from cheats to walkthroughs, machinima to illustrations, and "is the first step towards participation in a player community" and "can be seen as a player's creative response to the limitations of the rule set imposed by the game" (2006: 135). Variations on how to play the card games alongside websites that offered cheats and guides to the video games, or displayed new artwork and character designs, allow fans to participate in the reordering of the official Pokémon universe.

Yet, as Louisa Ellen Stein asserts (2006: 247), "Within the many diverse forms of fan creativity online, we can identify a central tension between two defining fannish concerns: expansiveness and limitation." Expansiveness refers to the nature of the meta-text which allows for open readings due to the multiplicity of characters and narratives. Limitation, as a consequence, refers to the restrictive nature of the relationship between original source text and those fan stories on which it is based. Julian Sefton-Green discusses this concept specifically in connection with the Pokémon games, as players negotiate the "inherent tension between understanding 
the game as logical system versus as an imaginative world" (2004: 161). The game, after all, is designed and coded according to a set of rules; players can only explore and deviate from their objective according to how much extra creative space creators have added into the game. With this in mind, we might also consider the Pokémon fan theories and fanfic found online as evidence of this tension: that the game universe and associated characters offer fans an expansive meta-narrative which prompts them to fill gaps in backstory either to enhance their own game play or solve mysteries supposedly left by game designers; but, at the same time, that there are certain limitations that prevent fan theories from ever coming true because new games and characters created supersede those made up by fans - thus reasserting the primacy of the game universe and how fans should be engaging with the Pokémon text. Nonetheless, as Ken McAllister states, fan productivity even at the smallest level is an important part of the gaming industry - an economic force in its own right. Fan made texts provide gamers "with a tie-over fix between game-play sessions", as well as offering "an immersive experience for players newly enthralled by a game" (2004: 22).

In the following analysis of some of the most prevalent fan conspiracy theories circulated online we can see how gamers and fans are attempting to engage with and enhance the metatext (the established game universe, characters and backstories alongside fan fiction and theories) beyond what is allowable in the virtual gaming environment. Speculative narratives based on tiny gaps and inconsistencies in the official backstory circulate through the online community, adding depth and a sense of authenticity to areas where fans identify a lack. Lesley Goodman argues that "fans are hard on creators and source texts because the fannish impulse is to maintain the integrity of the fictional universe at the expense of the integrity of the 
creator(s) and the text itself" (2015: 669). Fans want to both maintain coherence of the fictional world and storyline but also assert their own superior appreciation of the text over the original creator's. This might also be considered part of Stein's "expansiveness-limitation" dynamic cited above as it is shaped by fans' fidelity to an original universe they're not only expanding through paratextual production, but also through the reordering (or curating) of the original world through their conspiratorial expansion. ${ }^{2}$ Fan agency, in this case, is not only an exercise in maintaining the inherent qualities of the Pokémon world, but it is also about protecting and preserving fan identity against the potential intrusions from game creators who may seek to fix problems and reassert canon over new fan theories.

Through a survey of nine Pokémon fan websites that list conspiracy theories I have identified two types of story: the first is specially related to the original Red/Blue/Green games and software, explaining away glitches and other inconsistencies found within the game by making them part of the Pokémon canon; the second is primarily metatextual and stems more from the fictional universe expanded and explored in the television series, films and comics. So, for example, the theory that pokémon can die originates online and is based on players sharing thoughts on why Red (the main playable character in the first Nintendo game) does not encounter Blue's Raticate again after defeating him early in the journey. This theory is fuelled by the fact that within the game the Blue character is later found in a graveyard where Red battles him - only this time Blue does not use his Raticate to fight. Unsurprisingly, fan message boards are awash with speculation that if a

\footnotetext{
2 I want to thank anonymous reviewer 1 of this article for suggesting the notion of curation on behalf of Pokémon fans who write conspiracy theories about the game glitches and storyline. Indeed, I would argue that fans are not only "curating" the storyworld through their fiction but they are also "curating" the actual conspiracy theories by listing and sorting them online in the form of top ten lists (see my explanation of the fan websites which contain these theories in note 2).
} 
character's pokémon like Raticate can die, could Ash's Pikachu?! Outside of the game the second form of conspiracy theory circulated by fans revolves around the expansion of the narrative backstory; typically either how some fans draw connections between pokémon character designs, inspiring the creation of noncanonical evolutions, or how the fictional universe came into being. For example, one theory proposes that the Pokémon world is the result of a global war, nuclear fallout and the spread of a terrible disease following experiments with matter transference (how pokémon turn into energy to fit inside poke balls). Fan history argues that by 2081 science has perfected the technology so that it no longer harms humans and thus Ash is able to start his journey at the age of ten.

The table below provides a summary of the most popular and circulated fan conspiracy theories listed on Pokémon fan blogs and gaming websites. I have cross referenced those game related conspiracy theories with their expanded universe versions where the former clearly informs and then develops into the latter. So, for example, where Lt. Surge in the original Red/Blue/Green game states that most adult men died in the Great Pokémon War this is later made canon in the television series and used by fans as the explanation for why there appears to be hardly any middle aged adult characters in either any of the subsequent games or the film/television spin-offs. Other stories I have listed separately. ${ }^{3}$

Figure 1: The Most Popular Fan Theories

\begin{tabular}{|l|l|}
\hline Game/Design Related Conspiracies & Expanded Universe Related Theories \\
\hline Most adult men died in Great Pokémon & Most adult men died in Great Pokémon \\
\hline
\end{tabular}

\footnotetext{
3 The nine sites I studied listed conspiracy theories in orders of 5, 6, 7 and 10. One site, the Pokémon Wiki, listed mainly evolutionary theories while gamer sites tended to concentrate on game related theories. Many of the stories appear multiple times across different lists and several sites have fan message boards with threads discussing the reliability of evidence for the theories and providing new evidence to either support or contest the original. See the Website References for a full list of sites analyzed.
} 


\begin{tabular}{|c|c|}
\hline War (Lt. Surge in Red/Green/Blue) & War (Lt. Surge Kanto season 1) \\
\hline $\begin{array}{l}\text { Ditto a failed Mew clone (appearance } \\
\text { and backstory of Mew's origins) }\end{array}$ & $\begin{array}{l}\text { Ditto a failed Mew clone (appearance } \\
\text { and backstory of Mew's origins) }\end{array}$ \\
\hline $\begin{array}{l}\text { Pokémon can die (Blue's Raticate not } \\
\text { seen again) }\end{array}$ & $\begin{array}{l}\text { Death in the Pokémon universe (ghost } \\
\text { types and backstories of certain } \\
\text { characters: Yamask, Duskull, Lampent) }\end{array}$ \\
\hline $\begin{array}{l}\text { MissingNo (glitch in Red/Blue where } \\
\text { developers supposedly missed out a } \\
\text { pokémon or it stands for a pokémon left } \\
\text { in its ball too long) }\end{array}$ & $\begin{array}{l}\text { MissingNo (glitch in Red/Blue where } \\
\text { developers were meant to have Marowak } \\
\text { evolve into Kangaskhan) }\end{array}$ \\
\hline $\begin{array}{l}\text { Kangaskhan is mother of Cubone (who } \\
\text { evolves into Marowak) but if she dies } \\
\text { then Cubone adopts her skull to wear } \\
\text { when orphaned }\end{array}$ & $\begin{array}{l}\text { Kangaskhan is mother of Cubone (who } \\
\text { evolves into Marowak) but if she dies } \\
\text { then Cubone adopts her skull to wear } \\
\text { when orphaned }\end{array}$ \\
\hline $\begin{array}{l}\text { Mount Moon in Kanto is a dormant } \\
\text { volcano }\end{array}$ & $\begin{array}{l}\text { Mount Moon in Kanto is a dormant } \\
\text { volcano }\end{array}$ \\
\hline $\begin{array}{l}\text { Pokémon can convert matter into energy } \\
\text { (in and out of poké ball) }\end{array}$ & $\begin{array}{l}\text { Pokémon can convert matter into energy } \\
\text { (in and out of poké ball) }\end{array}$ \\
\hline $\begin{array}{l}\text { Kabutops (prehistoric pokémon from } \\
\text { Kanto) is a Genesect when covered in } \\
\text { Team Plasma armour in Unova }\end{array}$ & $\begin{array}{l}\text { Kabutops (prehistoric pokémon from } \\
\text { Kanto) is a Genesect when covered in } \\
\text { Team Plasma armour in Unova }\end{array}$ \\
\hline $\begin{array}{l}\text { Pokémon invented language from battle } \\
\text { cries }\end{array}$ & $\begin{array}{l}\text { Pokémon invented language from battle } \\
\text { cries }\end{array}$ \\
\hline Jynx is a succubus (based on design) & $\begin{array}{l}\text { Jynx is a succubus/racist (based on } \\
\text { design) }\end{array}$ \\
\hline \multicolumn{2}{|l|}{ Red's dad follows you through the game } \\
\hline \multicolumn{2}{|l|}{$\begin{array}{l}\text { Koffing and Weezing are products of } \\
\text { Team Rocket's experiments (design and } \\
\text { abandoned labs in game) }\end{array}$} \\
\hline \multicolumn{2}{|l|}{$\begin{array}{l}\text { You mum pays for your Pokémon Centre } \\
\text { visits (narrative of leaving the nest) }\end{array}$} \\
\hline \multicolumn{2}{|l|}{$\begin{array}{l}\text { Pokémon evolve to get attention from } \\
\text { you or dislike for you (design of some } \\
\text { pokémon and the fact you have to trade } \\
\text { some to evolve them) }\end{array}$} \\
\hline \multicolumn{2}{|l|}{$\begin{array}{l}\text { Black and White Games take place in } \\
\text { post } 9 / 11 \text { world (Unova region resembles } \\
\text { Manhattan Island with dystopic } \\
\text { wasteland) }\end{array}$} \\
\hline \multicolumn{2}{|l|}{ Digimon are digital Pokémon } \\
\hline \multicolumn{2}{|l|}{$\begin{array}{l}\text { Ghost Girl character in } X / Y \text { related to } \\
\text { new Hoopa pokémon }\end{array}$} \\
\hline \multicolumn{2}{|l|}{$\begin{array}{l}\mathrm{N} \text { is really a Zoroark seen in Black and } \\
\text { White }\end{array}$} \\
\hline \multicolumn{2}{|l|}{ Humans are non-evolving pokémon } \\
\hline \multicolumn{2}{|l|}{$\begin{array}{l}\text { Humans are not native to the world of } \\
\text { pokémon }\end{array}$} \\
\hline $\begin{array}{l}\text { Wobbuffet's decoy body (its tail is really } \\
\text { it) }\end{array}$ & \\
\hline
\end{tabular}




\begin{tabular}{|l|l|}
\hline $\begin{array}{l}\text { Butterfree should be evolved form of } \\
\text { Venonat (based on design) but instead } \\
\text { evolves from Caterpie/Metapod; as a } \\
\text { consequence Venomoth should evolve } \\
\text { from Caterpie/Metapod (based on } \\
\text { design) }\end{array}$ & \\
\hline $\begin{array}{l}\text { Shellder evolves into Cloyster but if shell } \\
\text { falls off gas body inside becomes a } \\
\text { Gastly }\end{array}$ & \\
\hline $\begin{array}{l}\text { Psyduck should be called Golduck } \\
\text { (based on colour) }\end{array}$ & \\
\hline $\begin{array}{l}\text { Dialogue in Red/Blue predicts Munna } \\
\text { from Black and White (a pink chunky } \\
\text { pokémon with floral patterns) }\end{array}$ & \\
\hline $\begin{array}{l}\text { Silver is the father of Maxie (Omega } \\
\text { Ruby characters based on design } \\
\text { similarities) }\end{array}$ & \\
\hline $\begin{array}{l}\text { Parasect is controlled by mushroom on } \\
\text { its back which has taken over since } \\
\text { evolving from Paras }\end{array}$ & \\
\hline & \\
\hline & $\begin{array}{l}\text { Arceus used Unown to create the } \\
\text { universe (ties into Sinnoh region legend) }\end{array}$ \\
\hline & $\begin{array}{l}\text { Slowpoke is omniscient (not as stupid as } \\
\text { people think) }\end{array}$ \\
\hline & $\begin{array}{l}\text { Ash is in a comma from the very first } \\
\text { episode (all stories after Pikachu shocks } \\
\text { him are dreams; that's why he doesn't } \\
\text { age) }\end{array}$ \\
\hline $\begin{array}{l}\text { Gengar is Clefable's shadow/ghost (fan } \\
\text { art has allowed fans to match their } \\
\text { frames and outlines) }\end{array}$ \\
\hline $\begin{array}{l}\text { Ash Ketchum is immortal (survives battle } \\
\text { between Mew and Mewtwo in first movie) }\end{array}$ \\
\hline $\begin{array}{l}\text { Voltorb is a poké ball possessed by } \\
\text { Haunter (accounts for why inanimate } \\
\text { balls become animated; eyes look like } \\
\text { those of Haunter) }\end{array}$ \\
\hline $\begin{array}{l}\text { Aerodactyl are prehistoric Zubats (fits } \\
\text { with stories about fossilised pokémon) }\end{array}$ \\
\hline Bulbasaur's bulb is an Oddish \\
\hline Sokémon have a form of Stockholm \\
Syndrome (form bounds with their \\
captors/trainers)
\end{tabular}




\begin{tabular}{|l|l|}
\hline & Magma, Plasma etc.) \\
\hline & Pikazard can exist (Ditto takes form of \\
fan favourite whilst also taking on \\
attributes of heat from Charizard) \\
\hline History of pokémon world result of global \\
war and disease caused by matter \\
energy transference experiments 2027- \\
2081 (Ash turns 10 and starts his \\
journey) \\
\hline
\end{tabular}

The preponderance of design/game conspiracy theories and fan stories surrounding the first generation of games and 151 pokémon characters suggests that fans felt the need to build in a meta-narrative where one did not previously exist. Furthermore, as David Surman argues, the first 151 have become iconic; representative of the franchise's commodification of Japanese anime culture across the globe and illustrative of "the dichotomous paradigms of 'cute' and 'cool' that shape the zeitgeist of Pokémon" (2009: 158). ${ }^{4}$ As the animated series and subsequent games were released with more pokémon and human characters introduced the need for fans to fill the gaps correspondingly decreased. However, that these stories re-circulate online and persist as part of a fan canon, despite the expansion of the Pokémon universe in new games and series such as the latest Sun and Moon, indicates the importance of narrative in the affective relationship fans share with both the game and television text. ${ }^{5}$ Indeed, one informs the other so that game/design conspiracies about glitches in the original Red and Blue games have been written in as real narrative history. Fan explanations that attempt to make sense of the mysterious and unexplained act to inform and stabilise a previously

\footnotetext{
${ }^{4}$ Little surprise then that the pokémon you can catch in the new Pokémon Go mobile app are the original 151 characters.

${ }^{5}$ As can be gleaned from the posting dates for the online conspiracy theories in the reference list many coincide with the release of the Pokémon games, $X$ and $Y$, which came out in 2014. Clearly, marketing and fan buzz meant that game sites and fan wikis were keen to focus on some of the weird and wonderful stories that have been around since the first games in the 1990s.
} 
fluctuating and inconsistent narrative that had not been fleshed out by the writers and game designers in the early years.

I would argue that the conspiracy theories listed above are examples of fan fiction, stories written by fans who have an intimate knowledge of the original text but feel it somewhat lacking in depth, detail or characterization. The lists of different theories, attempts at explaining game glitches, exploring narrative history or providing more detailed backstories for characters, represent an ongoing process of making and remaking the Pokémon story world. However, the fact that so many theories and lists exist suggests that the Pokémon world is in a constant state of work in progress, each theory is a building block - an additional story detail - that contributes to the whole fantext. For Kristina Busse and Karen Hellekson, the "fantext, the entirety of stories and critical commentary written in a fandom (or even in a pairing or genre), offers an ever-growing, ever-expanding version of the characters. These multitudes of interpretations of characters and canon scenes are often contradictory yet complementary to one another and the source text" (2006: 7). Yet, while the Pokémon universe is so large - and growing bigger with every new game released and new pokémon designed - it is surprisingly devoid of narrative history. There is no official handbook outlining the parameters of the Pokémon world other than the game guides that discuss tactics, rules, levels, statistics, and game geography (where players have to travel to collect new pokémon and compete in new battles). This lack of official history means that fans take it upon themselves to write their own and adopt it as part of the official canon. The stories in effect become "fanon", fanfic that was never part of the canon but has become "generally accepted and used by other writers" (Pugh, 2005: 41). Therefore, the lists of conspiracy theories shared online are important contributions to the Pokémon universe because 
they extend it beyond the world seen on screen - both game console and television - and make it more tangible, complete and real.

In her work on popular conspiracy theories Clare Birchall argues that they are not simply about paranoia and seeing enemies where they may not exist but reflect a deeper desire by those who spread and read them to engage in a dialogue, producing new knowledge in an ever increasing, and technology driven, system of information. Conspiracy theory is "a knowledge-producing discourse - characterized by a collection of statements and texts shaped within and by different (para)institutional contexts which promote a particular knowledge about the world" (Birchall, 2006: 34). Further, the mainstreaming of conspiracy as a mode of response and form of media production by fans is indicative of a contemporary shift in online culture, where the web becomes the site for a cottage industry of conspiracists who can maintain a webpage and respond to news as and when it becomes public (37). In support of this, Peter Knight contends that "conspiracy theory is an integral part of the infotainment culture at the turn of the millennium, hovering somewhere between committed belief and the culture of consumption" (2000: 45). In this context, then, Pokémon fan stories are all about knowledge production shaped by the textual and paratextual contexts of the game and television series in an era of convergence. Certainly, specific stories that hypothesise about the nature of the pokémon universe, its geography, and the history of how it came into being are all about promoting "a particular knowledge about the world".

We can also draw connections between the nature of gaming and the types of stories being circulated by fans. Interactivity is an important part of gaming, allowing "players to explore a virtual space and context nonsequentially, generating causes, observing effects and reacting to the causes and effects generated by other players 
or by random events" (McAllister, 2004: 36). Thanks to this, games can be considered "alive" (Crawford, 1984: 8), constantly evolving as a result of all the interpersonal material generated and inputted into the game environment. Likewise, as new stories and theories are shared online the virtual site of paratextual knowledge production creates more space for fans to influence how old and new fans interpret and relate to the Pokémon world they read about. This in turn influences how they read the game and television series as they play and watch. In other words, as the fictional universe and narrative backstory expands through the invention and addition of new theories to the fanon the fans' understanding of the internal workings of the game and potential motivations for some of the characters and monsters as they play also evolves. A narrative written to fill in the gaps of a game devoid of detailed overarching story thus becomes the lens through which not only the games are played but also how the world is talked about online.

Conspiracy becomes truth and the search for evidence to back up theories drives gamers to play on and unpick more holes and uncover more mysteries. As Michael Barkun suggests, "Those who subscribe to such constructs do not ask that the constructs be taken on faith. Instead, they often engage in elaborate presentations of evidence in order to substantiate their claims" (2003: 7). We can see this in the multitude of fan art positioned alongside these theories online, where fans copy, paste, and illustrate their ideas with pictures of pokémon and their evolutionary chains or maps of the various regions found in the fictional universe.

\section{Figure 2: The Great Pokémon War}



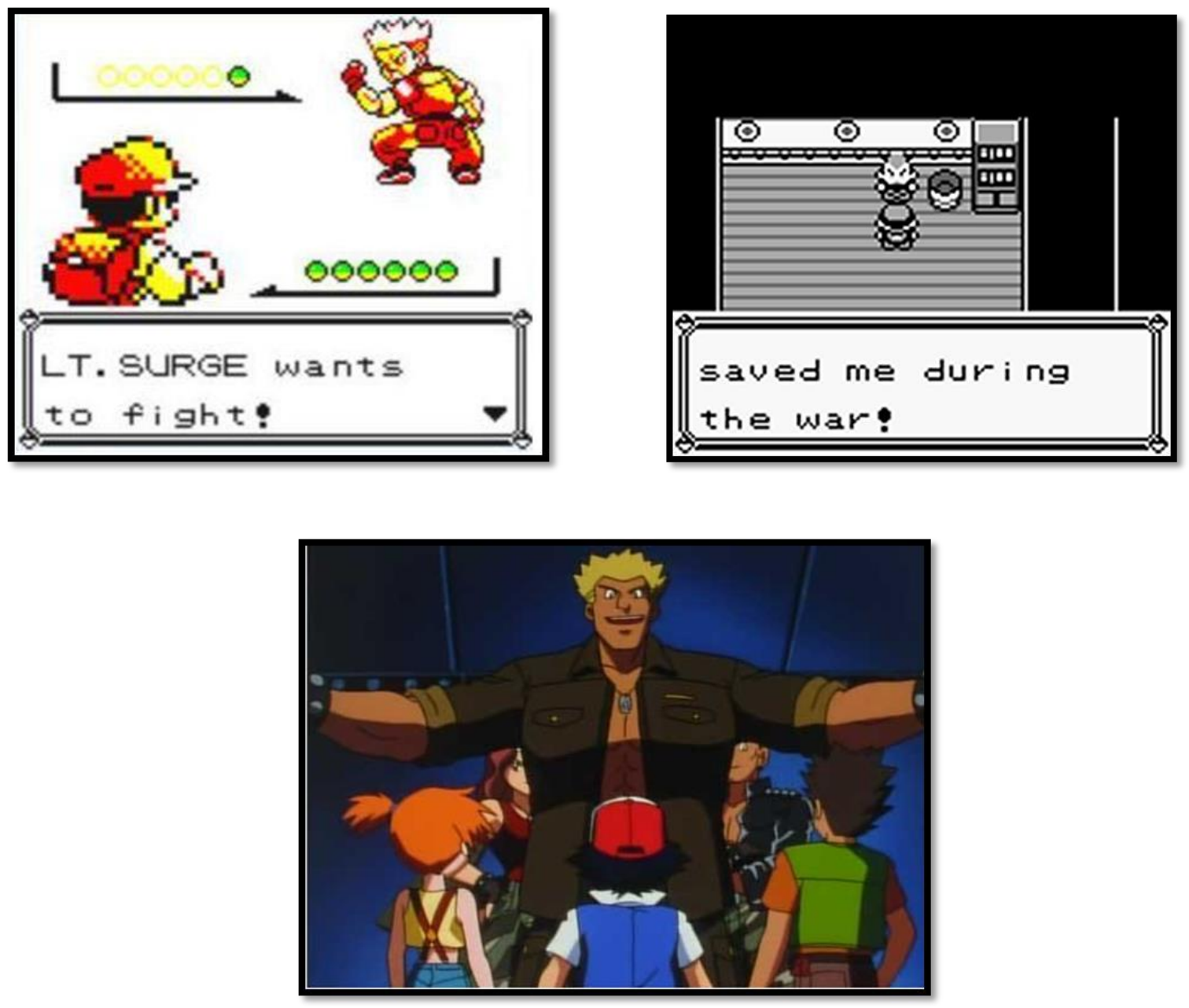

From an encounter with the gym leader Lt. Surge in the Red, Green and Blue video games fans have created a mythic story of The Great Pokémon War. Surge tells Red that his pokémon Raichu "saved me during the war", but which war is left unsaid. This one line has spawned numerous theories about a mysterious conflict and how men and pokémon were paired off to fight in it. Indeed, this is an example of how the game narrative has influenced and inspired fans to expand the story beyond the cryptic claims of Lt. Surge. As outlined above, the idea of the Great Pokémon War has become fanon - written into the fictional history of how humans and pokémon came to exist side by side in an idyllic world. Some fans have even mapped out a chronology - with the war as catalyst for the scientific developments that would eventually allow humans to capture and collect pokémon - tying this back 
into what is actually canonical within the game universe: Red (or Ash in the television series) starting off on his journey to be a Pokémon Master at the age of 10. Indeed, the war was even mentioned in the first series of Pokémon, with Ash, Misty and Brock encountering Surge and challenging him for a gym battle, but again no details were revealed. The fan conspiracy shared online thus remains an integral part of the series' metatext - undisputed and adding context for Surge's close relationship with his Raichu depicted in the episode. Like many of the longstanding theories, The Great Pokémon War has encouraged other fan stories that attempt to explain other oddities in the Pokémon universe. Fans often theorize why there are hardly any middle aged adults in the game as television series: most of the main characters are children (Ash is perennially 10) and the majority of adults encountered are either motherly figures (like Ash's mum) or old, depicted as wise but with a youthful spirit. The Great Pokémon War is therefore referenced by fans who suggest that middle aged men were called away to fight (like Surge) and many did not return home when it ended.

Figure 3: A Post 9/11 New York
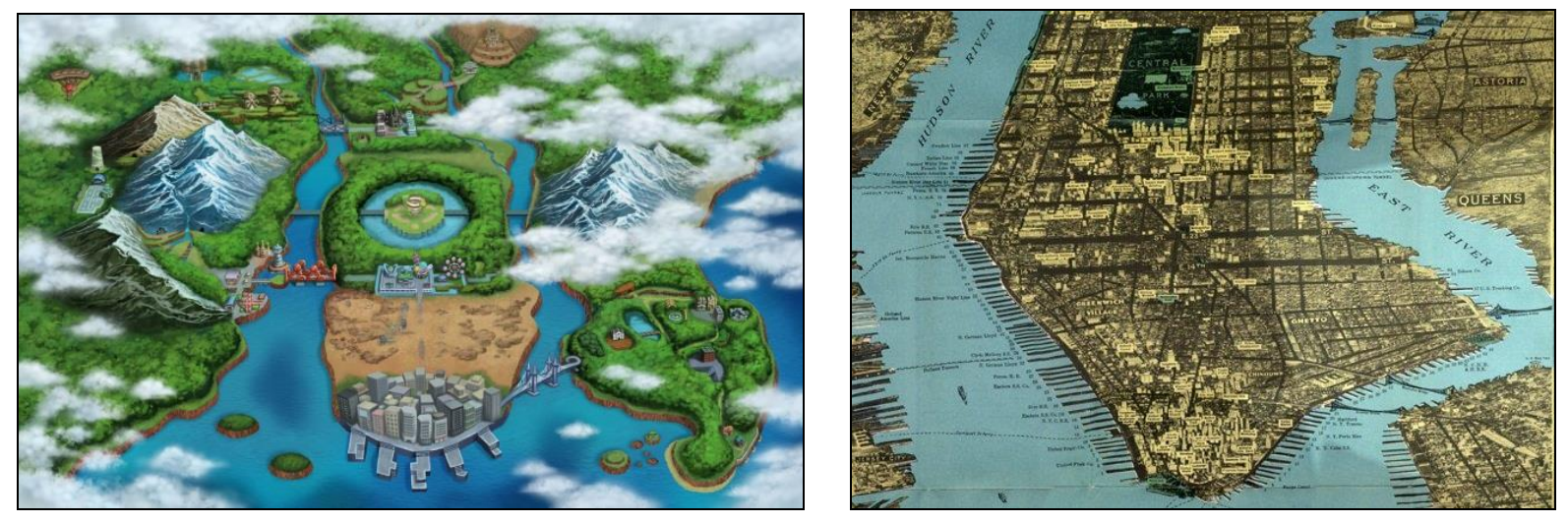

In continuing to flesh out the history of The Great Pokémon War some fans often use visual material to provide supporting evidence for their theories. The theory 
that Pokémon is set in a post $9 / 11$ world grew in popularity following the release of the Black and White games in 2010. That game followed Ash's journey into the Unova region, with new pokémon to catch and another tournament to enter. ${ }^{6}$ Its geography, as shown in the image on the right above, is described by one fan as being more like Manhattan than any region in Japan. Matching a screenshot from the television series with a map of Manhattan Island they describe how the desert wasteland in Unova corresponds to where Ground Zero is in New York City, using well-known sites to back up their point:

You can see Central Park up top, which is matched by Unova's lush pokeballshaped pond. Then there's the bustling financial district on the southern tip, which again is mirrored in Unova. You can even see a facsimile of the Brooklyn Bridge leading to Unova's eastern side. Everything in this region of the Pokemon world seems to have a real-world counterpart, so what's up with the dead center Dust Bowl? It doesn't belong... unless you think it's supposed to be Ground Zero. It is about right area, after all. Heck, there's even a bunch of construction workers in the area when you pass through. (Cooper, 2014)

Clearly this fan is hypothesizing and claiming much from little actual textual evidence but nonetheless such a theory becomes part of the fantext created around the Pokémon universe - substantiating and validating the pre-established fanon of The Great Pokémon War.

Figure 4: The MissingNo.

6 The Pokémon world is not officially named yet it is split into regions which are named and do differ in terms of geography, types of pokémon, and local customs and beliefs. Each region also holds its own tournament, which provides the impetus for Ash and Pikachu to continue their journey and encourages him to become a Pokémon Master. The regions charted so far are: Kanto (where Ash lives), Johto, Hoenn, Sinnoh, Unova and Kalos. 

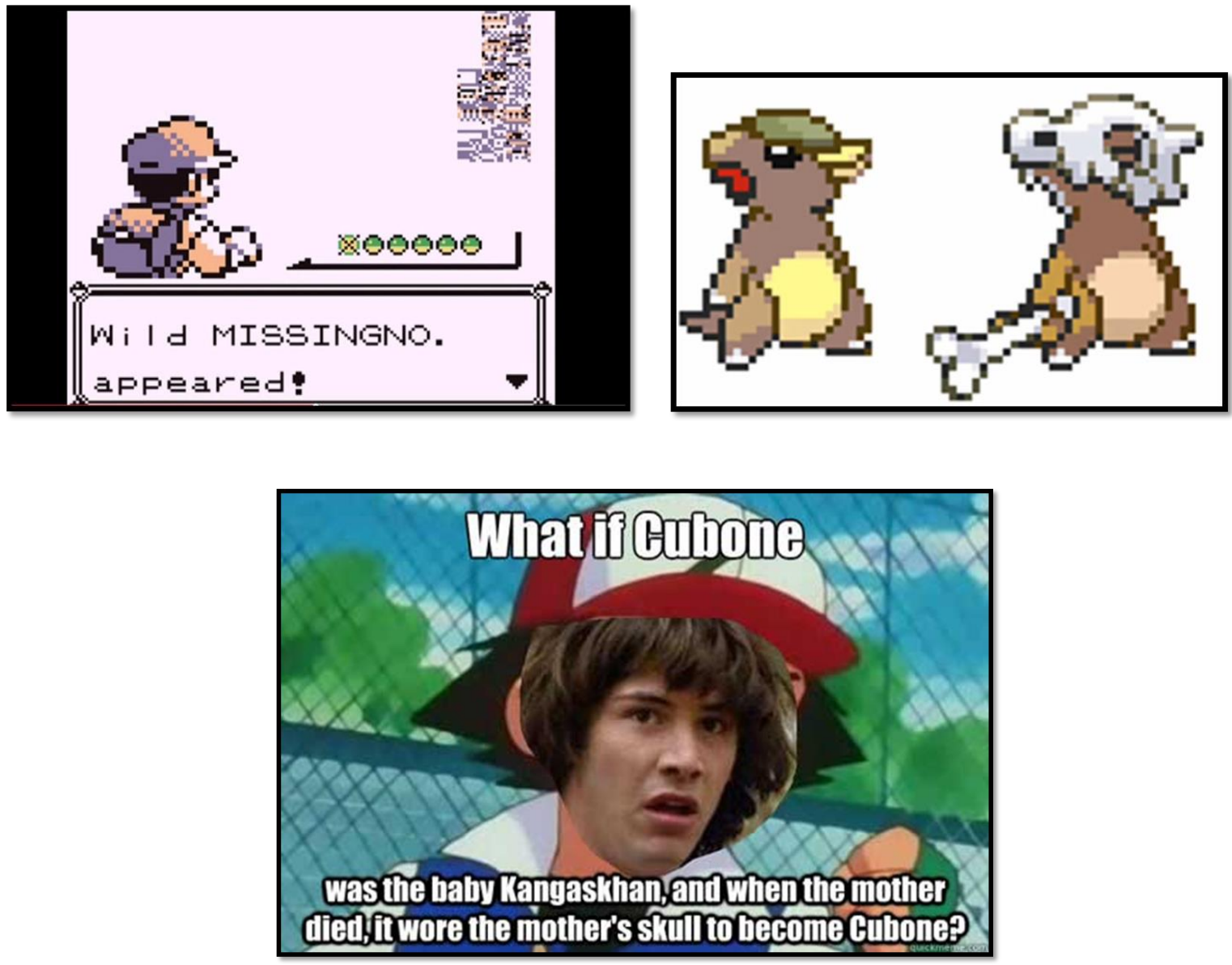

The fan theory of The Missing No. again relates to the Red, Blue and Green versions of the Pokémon games. When exploring Kanto the Red character encounters a pokémon who is referred to as "MISSINGNO.", an abbreviation of "missing number", a glitch in the game that some fans have explained by theorizing that the designers made a last minute change and took away an evolution to the Kangaskhan pokémon. Instead of changing the game code the designers moved the missing evolution to a number that didn't exist in the original list of 151 pokémon thus creating a MissingNo. that Red still has to fight in order to progress through the game. This conspiracy theory has grown beyond the limits of the game software over the years, becoming an established work of fanon. Fans have used the glitch to justify claims that whilst Kangaskhan does not evolve its offspring (who lives in its pouch) is forced to leave when its mother dies and evolves into the pokémon 
Cubone which is described in some game guides as wearing the skull of its dead mother. Indeed, this theory is given further credence with the description of Cubone's evolved form of Marowak, described as having "toughened up from this lack of maternal care" (Roncero-Menendez, 2013). The death aspect of this theory clearly relates to another theory I discussed earlier, that pokémon can die as in the example of Blue's Raticate, and to the fact that ghost type pokémon were introduced into the Pokemon universe in the Gold and Silver versions of the game in 1999. If death and ghost pokémon exist in the fictional narrative then the fan theory that Cubone is the offspring of Kangaskhan is not so far-fetched in terms of alternative evolutions.

Figure 5: Alternative Evolutions ${ }^{7}$
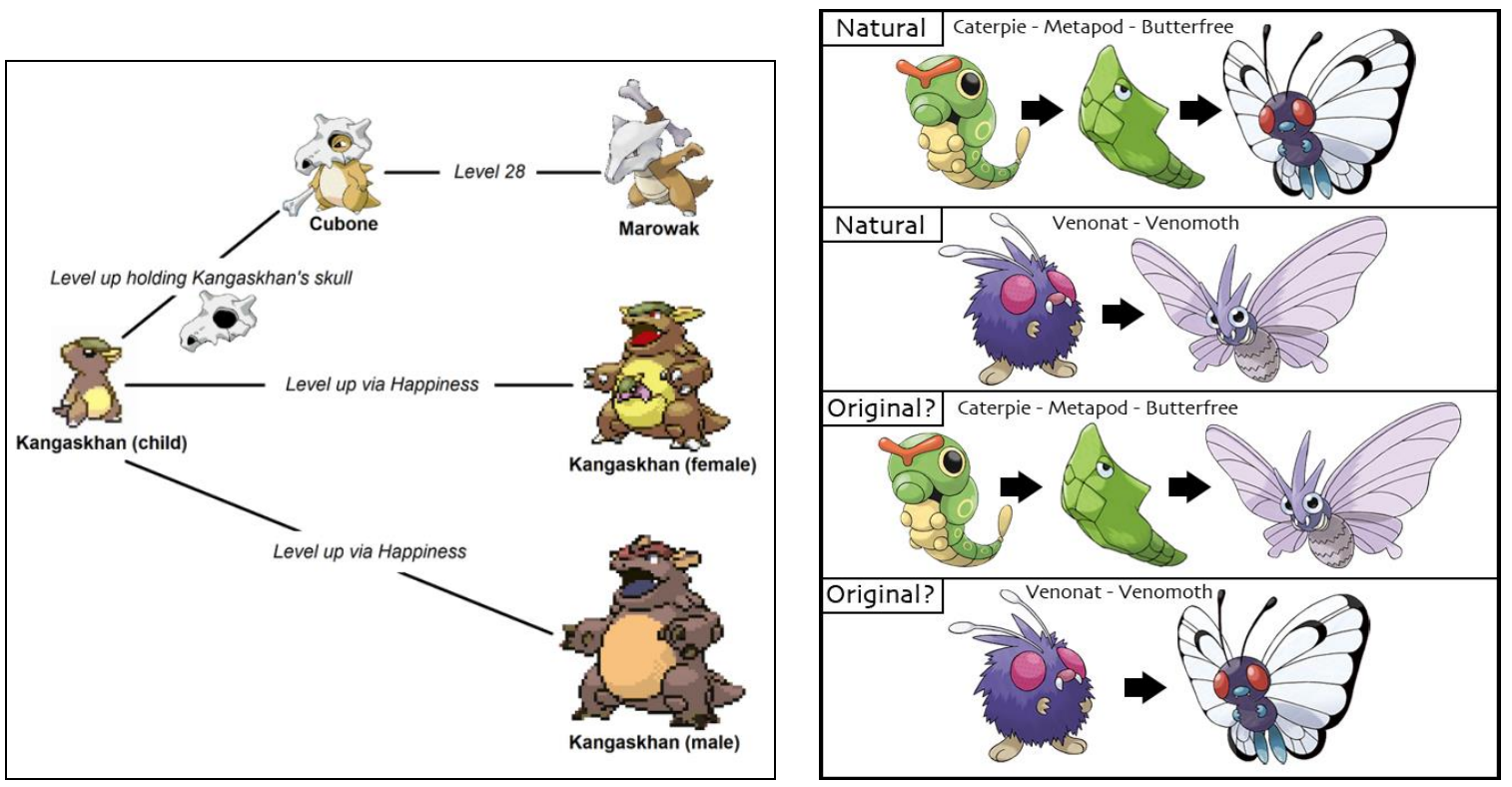

\footnotetext{
7 Pokémon are categorized by type - there are 18 types in total - with many pokémon combining characteristics and abilities of two or more. The types are: bug, flying, normal, dragon, ghost, poison, electric, grass, psychic, fighting, ground, rock, fire, ice, water, dark, steel and fairy (new to the $X$ and $Y$ games). While most pokémon are plentiful in number across regions some are rare (emphasizing the collecting nature of the franchise) and are described as either legendary or mythical, having inspired stories and tales amongst the people who live in the different regions (for a full list of pokémon up to the $X$ and $Y$ games see Silvestri, 2012).
} 

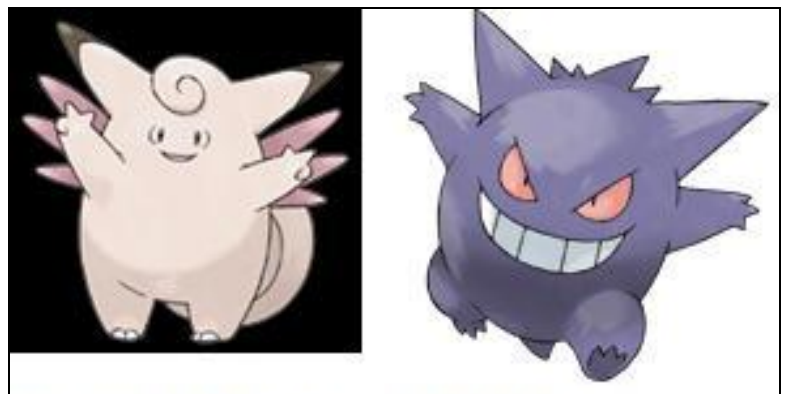

Same hands, ears, and feet. Wings became back spikes, hair curl spiked, and tail uncurled. Gengar is said to be a shadow Pokemon. Enjoy your mindfuck.

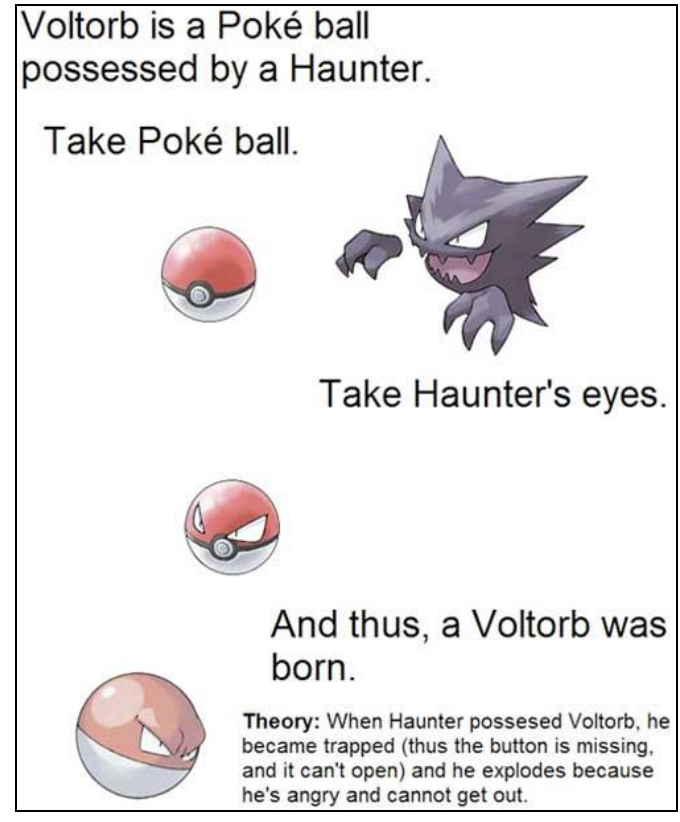

Without a doubt, alternative evolutions theories are some of the most popular on the fan created lists. Using graphics, fan art and box text to support hypotheses fans come up with ingenious claims for why some official evolutions might not be so convincingly drawn. As can be seen in the examples above, the MissingNo./Kangaskhan theory is a prime example of an alternate evolution - this particular piece of fan art includes fake power ups that one might achieve in the actual game to justify the claim that Cubone evolves from the skull-wearing baby (see Anon, n.d.). Similarly, taking inspiration from the designs of Butterfree and Venomoth some fans believe that their evolutionary chains were mixed up by the designers and the original look of their pre-evolved forms suggests that they should be the other way around (see Yumeka, 2013). Early designs for two of the oldest pokémon, Clefable and Gengar, suggest connections between the two characters are more than just aesthetic. Some fans consider that Gengar, described as a shadow pokémon, is the mischievous shadow form of the fairy type Clefable despite the fact that each has their own unrelated evolutionary chain (see Yumeka, 2013). And the last alternative evolutions theory shown above again connects two 
previously distinct pokémon, Voltorb and Haunter. The former, looking like a poké ball, is possessed by Haunter (who is evolved from the ghost type Ghastly), thus becoming Voltorb. The design of the eyes and the exploding nature of this character are used in this theory as evidence for a pokémon possession (see Leadbeater, 2014).

Figure 6: Ash's Coma
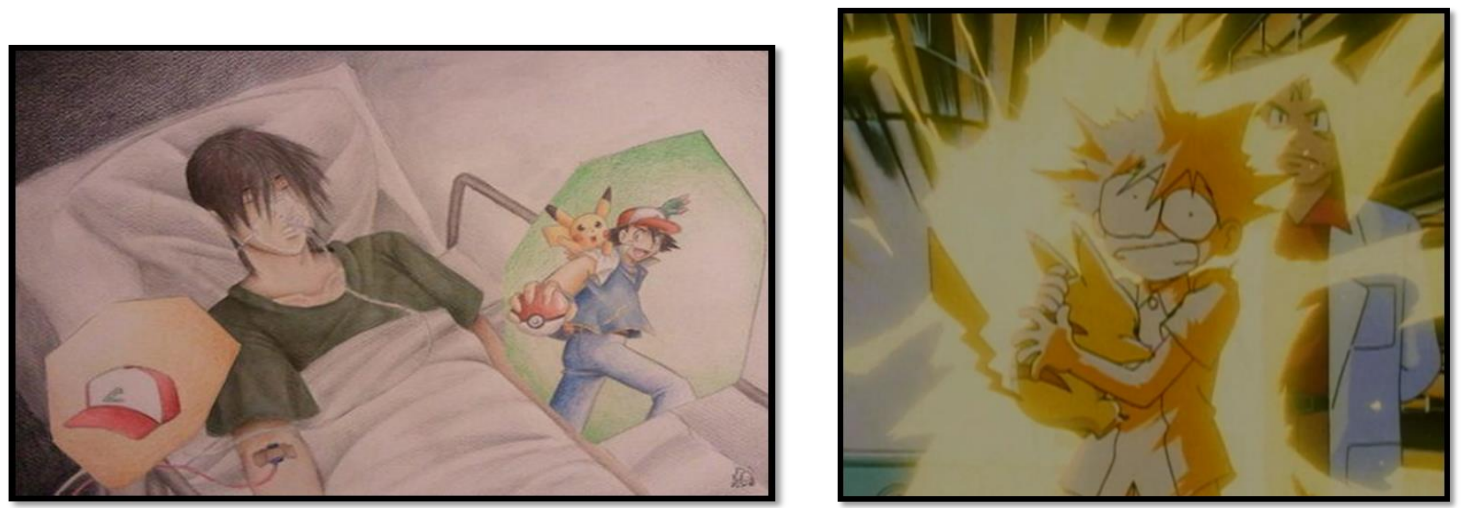

The most metatextual fan conspiracy that has become fanon is the theory of Ash's Coma. Inspired by the narrative of the television series, rather than any game glitch or character design, many fans explain the fact that Ash never appears to age despite him traveling for several years and meeting fellow trainers who set off at the age of 10 - because all his adventures are happening in a dream state while he lays in a coma. In fact, he never started his journey in the Kanto region because he didn't wake up from the shock he received from Pikachu before they became friends shown in the very first episode of season one (see Yumeka, 2013). The creation of such a fundamental origin story by fans suggests that not only are they seeking some control of the series narrative (and justifying why Ash always remains a child) but they are trying to conciliate between the conflicting narratives of the game and television versions of the Pokémon universe. In the former, Ash (or Red as he is 
known) is not always the main playable character but in the latter he has remained the main protagonist and it is through him we understand and appreciate the various creatures and regions encountered in every season of the series. Indeed, as in any animated series, having a protagonist that is the same age as the intended target audience is crucial for its continued success and longevity (an in-joke often referenced by 10 year old Bart in The Simpsons). Ash's Coma would appear to be the best example of Alternative Universe (AU) fanfic, where fans can play with and within the official text without affecting the overall narrative but still feel they have a controlling stake in its metatextual creation.

It is worth mentioning here that as a Japanese game and anime text that crossed over to western culture, acquiring a devoted fan following both in Europe and North America, Pokémon and its associated conspiracy theories and fanfic discussed in this article can be considered part of otaku culture ${ }^{8}$ : "While 'otaku' is often used in America to mean anime/manga fan... some fans use it in a stronger sense, either using 'otaku' as a label of sorts for the media, art, genres, and characters they like or as a pejorative" (Eng, 2012: 92). While I have not focussed on the potential negative interpretations of Pokémon fan culture in this article one could argue that the pejorative associations between the franchise, its fans and recent moral panics about the Pokémon Go app show that otaku culture is still very much treated with suspicion in western media. However, having chosen to see the Pokémon fan culture surrounding the creation of conspiracy theories and expanded universe fanfic as part of a tactic to rewrite narrative where fans see gaps, glitches and opportunities for new stories, I would argue that the examples I have highlighted and discussed correspond to recent academic debates about the importance of

\footnotetext{
${ }^{8}$ I want to thank anonymous reviewer 2 of this article for suggesting the link between otaku culture and the cultural consumption of Pokémon fan stories.
} 
global otaku culture. Indeed, Pokémon has "come to symbolize and evoke a notion of 'Japan' globally" (Hjorth, 2011: 81). For Lawrence Eng, "Japanese fan culture and amine provided a set of referents that mobilized a unique subcultural imagination in diverse locations around the world" and this imagination is "a proactive response to certain shared conditions that youth encounter in media-saturated contexts, a response that has given rise to a transnational subculture" (2012: 102). I would also argue that this subculture - which relies on the Internet and new digital technologies to create and share new information from old and remediated texts - corresponds to what Louisa Ellen Stein terms "millennial fandom" where digital media allows us to see the tremendous amount of effort and labor fans put into making and sharing videos, fanfic, memes, tweets, blogs and art - providing access to "the processes of fan authorship" (2015: 138). The fans discussed in this article are authors that contribute to the continuing story of Ash and Pikachu. The Pokémon universe is in a state of work in progress, each theory is a building block - an additional story detail that contributes to the whole text.

\section{Conclusion}

The lists, memes and illustrated conspiracy theories suggest that Pokémon fans are not only engaged in what Birchall calls a conspiratorial "knowledge-producing discourse" promoting "a particular knowledge about the world", they are also trying to become part of it - creating a credible backstory that makes them authors and historians of the game's and the universe's ever-expanding narrative. Indeed, this strategy is indicative of both the participatory practices of fandom and the visual elements of the media form; in this case, anime. Marc Steinberg's discussion of what 
he terms anime's "media mix" provides a helpful framework through which we might understand what Pokémon fans are doing here. Media mix, a "term for the crossmedia serialization and circulation of entertainment franchises" (Steinberg, 2012: viii), shares much with Henry Jenkins' examination of contemporary convergence culture (2006). However, Steinberg traces a longer history of the term, suggesting that it starts with the emergence of anime on Japanese television in the 1960s. More than a style, anime is a mode of cultural production and consumption where animated characters and franchises mix and merge across multimedia platforms. Audience consumption of these franchises and animated characters is not only about possession (purchasing and collecting merchandise and images) but also about participation (entering the fictional world through the various incarnations of the characters in question). Thus, according to Steinberg (2012: 200),

the anime media mix simultaneously creates (1) the character merchandise as material object, (2) the world to which the character merchandise belongs, and (3) the character as immaterial connective agent guaranteeing the consistency of this ever-expanding world.

Both the Pokémon game narrative and fictional universe have been charted in numerous official manuals, walkthroughs and game guides. Anne Allison analyses one of the first to be produced by Nintendo for the original Red and Blue releases. Of the Illustrated Book of Pocket Monsters (1997), which contains maps, charts, pictures, lists and character biographies to help players master the gaming environment and develop their playing skills, she says "The organizing trope in this discourse is knowledge, directed to a fantasy world premised far more now on the invisible and unseen - what must be learned and charted through data - than on what is fetishistically known and revealed through bodily sites/sights of mecha 
transformation" (Allison, 2006: 207). The qualities of the game guide are centred on the attainment of knowledge, unveiling mysteries and solving puzzles through incremental progress and achievements in the game. The fan theories and conspiracies discussed in this paper clearly serve to extend this search for secret knowledge, providing evidence in illustrated form of a wider Pokémon universe, a fanon, which exists online and created by the practices of fans.

So, just as current scholarship on video games have expounded upon the relationship between computer games and, what Paul Booth (2010) calls, the "philosophy of playfulness" in our contemporary media environment, Pokémon explicitly encourages fans to play with and within the narrative. In so doing new knowledge is produced and new stories are told. Just as a player searches the levels of each game, gradually discovering new pokémon and adding incrementally to their understanding of the game world, a fan uses the Internet to expand and enhance their knowledge of the fictional text and claims part of its creation. Participation is key to the Pokémon world but not just because you assume the role of a trainer tasked to compete in the Pokémon League. As a fan, author of conspiracy theories and alternate origin stories, you are able to participate through the rewriting of the game's metatext. According to Andrew Burn, "in fan art and writing" surrounding popular computer games "the representational system and game system pull apart" and those "fans whose interest lies in the rich and complex imagery and narrative of the game build on these structures" (2006: 102). Therefore, fan created content extends the game, taking it from one screen to another, but it also demonstrates how important narrative - and the sharing of it - is to the computer game fan community. 


\section{Website References}

Anon. (n.d), "Pokemon - Fan Theories Wiki", http://fantheories.wikia.com/wiki/Pokemon. Accessed 12 March 2015.

Cooper, H. (2012). "The Top 7... Most disturbing things about the Pokemon universe", http://www.gamesrader.com/top-7-most-disturbing-things-about-pokemonuniverse/. Accessed 12 March 2015.

Cooper, T. (2014). "7 Dark but Believable Pokemon Fan Theories", http://www.dorkly.com/post/711447/7-dark-but-believable-pokemon-fan-theories. Accessed 12 March 2015.

Cubria, K. (2014), "6 Pokemon Fan Theories That Actually Make A Lot of Sense", http://www.teen.com/2014/05/16/television/pokemon-theories-hidden-messages/. Accessed 12 March 2015.

Jedeikin, D. (2014), "These Fan Theories Might Change The Way You Look At 'Pokémon'”, http://www.smosh.com/smosh-pit/articles/fan-theories-might-changeway-you-look-pokemon. Accessed 12 March 2015.

Leadbeater, A. (2014), "7 Crazy Pokemon Origin Theories That'll Blow Your Mind", http://whatculture.com/gaming/7-crazy-pokemon-origin-theories-thatll-blow-mind.php. Accessed 12 March 2015.

Reed, A. (2014), "The Top 7... Weirdest theories about the Pokemon universe", http://www.gamesrader.com/top-7-weirdest-theories-about-pokemon-universe/. Accessed 12 March 2015.

Roncero-Menendez, S. (2013), "The 10 Most Bizarre Pokémon Fan Theories", http://mashable.com/2013/10/12/pokemon-fan-theories/. Accessed 12 March 2015.

Yumeka. (2013), "Top 10 Pokemon conspiracy theories”, http://animeyume.com/blog/2013/04/12/top-10-pokemon-conspiracy-theories/. Accessed 12 March 2015.

\section{References}

Allison, Anne (2006), Millennial Monsters: Japanese Toys and the Global Imagination, Berkeley: University of California Press.

Barkun, Michael (2003), A Culture of Conspiracy: Apocalyptic Visions in Contemporary America, Berkeley: University of California Press.

Birchall, Clare (2006), Knowledge Goes Pop: From Conspiracy Theory to Gossip, Oxford: Berg. 
Booth, Paul (2010), Digital Fandom: New Media Studies, New York: Peter Lang.

Buckingham, David and Sefton-Green, Julian (2003), "GottaCatch'em All: Structure, Agency and Pedagogy in Children's Media Culture," Media, Culture, Society, 25.3: 379-399.

Burn, Andrew (2006), "Reworking the Text: Online Fandom," in Computer Games: Text, Narrative and Play, Diane Carr, David Buckingham, Andrew Burn and Gareth Schott, Cambridge: Polity, 88-102.

Busse, Kristina and Hellekson, Karen (2006), "Introduction: Work in Progress," in Fan Fiction and Fan Communities in the Age of the Internet, eds. Karen Hellekson and Kristina Busse, Jefferson, NC: McFarland, 5-32.

Crawford, Chris (1984), The Art of Computer Game Design, Berkeley: Osborne/McGraw-Hill.

Dovey, Jon and Kennedy, Helen W. (2006), Game Cultures: Computer Games as New Media, Maidenhead: Open University Press.

Eng, Lawrence (2012), "Strategies of Engagement: Discovering, Defining, and Describing Otaku Culture in the United States," in Fandom Unbound: Otaku Culture in a Connected World, eds. Mizuko Ito, Daisuke Okabe, and Izumi Tsuji, New Haven: Yale University Press, 85-104.

Geraghty, Lincoln (2015), “An Evolutionary Journey: Pokémon, Mythic Quests and the Culture of Challenge," in Karin Beeler and Stan Beeler, eds. Children's Film in the Digital Age: Essays on Audience, Adaptation and Consumer Culture, Jefferson, NC: McFarland, 78-88.

Goodman, Lesley (2015), "Disappointing fans: Fandom, fictional theory, and the death of the author," The Journal of Popular Culture, 48.4: 662-676.

Harvey, Colin B. (2015), Fantastic Transmedia: Narrative Play and Memory Across Science Fiction and Fantasy Storyworlds, Basingstoke: Palgrave MacMillan.

Hills, Matt (2002), Fan Cultures, London: Routledge.

Hjorth, Larissa (2011), Games and Gaming: An Introduction to New Media, Oxford: Berg.

Jenkins, Henry (2006), Convergence Culture: Where Old and New Media Collide, New York: New York University Press.

Kent, Steven L. (2001), The Ultimate History of Video Games, New York: Three Rivers.

Kinder, Marsha (1991), Playing with Power in Movies, Television and Video Games: From Muppet Babies to Teenage Mutant Ninja Turtles, Berkeley: University of California Press. 
Knight, Peter (2000), Conspiracy Culture: From Kennedy to The X Files, London: Routledge.

McAllister, Ken S. (2004), Game Work: Language, Power, and Computer Game Culture, Tuscaloosa: The University of Alabama Press.

Pugh, Sheenagh (2005), The Democratic Genre: Fan Fiction in a Literary Context, Bridgend: Seren.

Sefton-Green, Julian (2004), "Initiation Rites: A Small Boy in a Poké-World," in Pikachu's Global Adventure: The Rise and Fall of Pokémon, ed. Joseph Tobin, Durham: Duke University Press, 141-164.

Silvestri, C. (2012), Pokémon: Essential Handbook, New York: Scholastic.

Stein, Louisa Ellen (2006), “'This Dratted Thing': Fannish Storytelling Through New Media," in Fan Fiction and Fan Communities in the Age of the Internet, eds. Karen Hellekson and Kristina Busse, Jefferson, NC: McFarland, 245-260.

. (2015), Millennial Fandom: Television Audiences in the Transmedia Age, lowa City: University of lowa Press.

Steinberg, Marc (2012), Anime's Media Mix: Franchising Toys and Characters in Japan, Minneapolis: University of Minnesota Press.

Surman, David (2009), "Pokémon 151: Complicating Kawaii," in Gaming Cultures and Place in Asia-Pacific, eds. Larissa Hjorth and Dean Chan, New York: Routledge, 158-178.

Tobin, Joseph (2004), "Conclusion: The Rise and Fall of the Pokémon Empire," in Pikachu's Global Adventure: The Rise and Fall of Pokémon, ed. Joseph Tobin, Durham: Duke University Press, 257-292. 